\title{
Early Experience In Pediatric Hepatic Resection at IOM, TUTH
}

Shah S, Kansakar P, Vaidya P

Department of Surgery, Institute of Medicine, TUTH, Maharajgunj, Nepal

Correspondence: Dr Surendra Shah, Residence, MCh (GI Surgery)

IOM, TUTH, Maharajgunj, Nepal

E mail: surendrashah@live.com

\begin{abstract}
Total 5 pediatric hepatectomy were performed at IOM TUTH during last 2 years. Three children were cases of hepatoblastoma and two were cases of symptomatic focal noduler hyperplasia (FNH). Two left hepatectomy for left hepatoblastoma, one right hepatectomy for right hepatoblastoma were performed and 2 non-anatomical resection of mass with $2 \mathrm{~cm}$ margin for focal nodular hyperplasia were performed. Median hospital stay was 7 days. Post operative period at hospital was uneventful. Three cases of hepatoblastoma received neoadjuvant and adjuvant chemotherapy. Among 3 cases of hepatoblastoma, there was one mortality due to severe sepsis when he was on adjuvant chemotherapy. Other 4 cases are living without recurrence.
\end{abstract}

Keywords: Focal nodular hyperplasia, Hepatectomy, Hepatoblastoma. 